\title{
On evapotranspiration and eddy covariance measurements corrections.
}

Bartosz M. Zawilski

5 CESBIO Université de Toulouse, CNES, CNRS, INRA, IRD, UPS, Toulouse, France

zawilskib@cesbio.cnes.fr

Abstract. Eddy Covariance (EC) technique is one of the most used technique monitoring Green House Gases (GHG) fluxes such as $\mathrm{H}_{2} \mathrm{O}, \mathrm{CO}_{2}, \mathrm{CH}_{4}$. Water vapor movement and corresponding air density fluctuations were corrected by Webb et al (1980) but not water vapor formation. Classic EC technique supposes mean air vertical speed nullity when it cannot be the 10 case because of water evaporation. Water is falling as a liquid, evaporating directly from soil surface, from shallow soil subsurface or either through vegetation transpiration and becomes a gas which corresponds to a notable volume expansion. Water vapor is mounting through atmosphere, compensating in a cloud and falling as a rain (liquid) again. Evaporation and corresponding volume expansion make mean vertical air speed positive (upgoing) and influence more or less a flux balance following concerned gas or energy. A simple accessing and corresponding correction for the half hourly summation is given

15 and applied to a 11-month real set of data. These corrections allow to explain, in part, most observed eddy covariance discrepancies.

\section{Introduction}

Eddy Covariance technique is very largely used for accessing green-house gases exchange between soil surface (including vegetation) and atmosphere. This technique was proposed and theorized in the middle of the last century by Montgomery (1948), Swinbank (1951), and Obukhov (1951), after creation of the sonics anemometers, it became relatively widespread. Use of EC supposes a large flat and homogeneous surface and allows to assets eddy exchanges trough few assumptions. For details Aubinet et al. edited a very complete book dedicated to EC from practical point of view and Burba et al. published an introduction to EC for non-experts. There is no need, and below the scope of this short note, to retrace the history or to go into detail of EC technique. The point raised by this note is to highlight a common assumption made about the mean vertical air speed nullity, its inexactitude, consequences and possible correction.

\subsection{EC formulation}

Standard EC made an assumption of the time-main wind vertical air velocity $\overline{w_{a}}$ nullity. Forming flux $F$ calculations formula using Reynolds decomposition, which means that all turbulent variable $\varepsilon$ can be decomposed into its time-mean part $\bar{\varepsilon}$ and its 
fluctuating part $\varepsilon^{\prime}$, after simplifications supposing spatial, horizontal homogeneity and air density fluctuations $\rho_{a}^{\prime}$ negligibility

30 the flux is given by a relatively simple one-dimensional Eq. (1):

$F=\overline{\rho_{a}} * \overline{w_{a}} * \bar{r}+\overline{\rho_{a}} * \overline{w_{a}{ }^{\prime}} \bar{r}$

With $r$ being the mixing ratio of the gas of interest defined by a density ratio $r=\frac{\rho_{c}}{\rho_{a}}$

Eddy covariance vertical air velocity time-mean nullity assumption $\overline{w_{a}}=0$ allows to simplify again flux calculation formula and retain only the turbulent part Eq. (2):

$35 F=\overline{\rho_{a}} * \overline{w_{a}{ }^{\prime} * \dot{r}}$

Neglecting main vertical air speed part (called in this note: correction flow) and given by Eq. (3):

$F_{c}=\overline{\rho_{a}} * \overline{w_{a}} * \bar{r}$

However, due to water evaporation, the main air vertical speed $\overline{w_{a}}$ cannot be nil and is mainly positive (upgoing) since water is falling on the soil surface as a liquid and is returning to the atmosphere as a gas which is accompanied by more than about 1245 -fold volume increase. The only exception is during the dew formation when the vertical mean air speed is negative. Dew formation versus rainfall is not negligible only in arid climates where during dry periods dew may reach up to $50 \%$ of rainfall water apport (Hao et al. 2012). For accessing the missing flux part as a rough estimation on can use few generic meteorological values. For $1 \mathrm{~mm}$ of precipitation, $1 \mathrm{~kg}$ of water fall on $1 \mathrm{~m}^{2}$ of soil surface. $1 \mathrm{~kg}$ of water is 1000/18=55.5(5) mol of water. After evaporation, supposing water vapor a perfect gas at standard pressure $P_{S}=101.325 \mathrm{kPa}$ and standard temperature $T_{S}=0{ }^{\circ} \mathrm{C}(273.15 \mathrm{~K})$, volume occupied by the water vapor is $22.4141 \mathrm{by}$ mol then the total volume for $1 \mathrm{~kg}$ of evaporated water is $22.414 * 55.5(5)=12451=1.245 \mathrm{~m}^{3}$. Volume increase is then about 1250 -fold initial water volume (real temperature is mainly higher than $\mathrm{T}_{\mathrm{S}}$ making volume increase even bigger than 1245 -fold). This volume increase, for $1 \mathrm{~mm}$ evaporated rainfall by year, causes a vertical, upgoing air speed $V_{e}=1.25 \mathrm{~m} /$ year which is rather small $\left(V_{e}=0.017 \mathrm{~mm} / \mathrm{s}\right)$ and well below the sensibility of any anemometer however, this speed is almost always in the same sense; upgoing, and when calculating correction flux; $F_{c}=\overline{\rho_{a}} * \overline{w_{a}} * \bar{r}$ (vertical mean air speed contribution to the total flux), we have to multiply $\overline{w_{a}}$ by $\bar{r}$ (time-mean mixing ratio) which is, of course, much bigger than the fluctuating part of the mixing ratio $\dot{r}$.

\subsection{Missed carbon dioxide flux part assessing}

Carbon dioxide volume mixing ratio follows a diurnal and seasonal pattern especially in the surface layer (less than $20 \mathrm{~m}$ from the surface) (Satar et al. 2016) where are implemented most of the eddy covariance towers, but as a minimum for carbon dioxide mixing ratio on can retain $400 \mathrm{ppm}-\mathrm{v}$ (volume parts per million). For mass flux measurements, the useful mixing ratio is mass mixing ratio. As carbon dioxide is about 1.67 heavier than air, the mass mixing ratio of carbon dioxide will be 1.67 -fold its volume mixing ratio. With $400 \mathrm{ppm}-\mathrm{v}$ we get then about $670 \mathrm{ppm}-\mathrm{m}$ (mass mixing ratio). As the mean vertical flux component is given by the Eq. (3), with $\overline{\rho_{a}}=1275.4 \mathrm{~g} / \mathrm{m}^{3}$ (also at standard pressure and temperature) $F_{c} \mathrm{CO}_{2}=1.074 \mathrm{~g}$ of $\mathrm{CO}_{2}$ by square meter and by year upgoing for one millimetre of evaporated precipitation. For $700 \mathrm{~mm}$ of 
yearly precipitation, $60 \%$ evaporated (mean rainfall evaporation rate given by Oki and Kanae 2006); $\mathrm{F}_{c}^{\mathrm{CO}_{2}} \approx 450 \mathrm{~g}$ of $\mathrm{CO}_{2} / \mathrm{m}^{2}$ a year that is about $125 \mathrm{~g}$ of equivalent carbon flux by square meter and by year. Neglecting $F_{c}^{\mathrm{CO}_{2}}$ when calculating total carbon dioxide flux $\mathrm{F}^{\mathrm{CO}_{2}}$ is neglecting about one third of yearly Net Ecosystem Production (NEP) of a maize plot or over twice a yearly NEP of a soybean plot (Verma et al. 2005). Correction carbon dioxide flux part is then absolutely not negligible and necessary.

\section{Eddy Covariance measurements correction}

Underestimation of the upgoing fluxes by eddy covariance can be corrected at least on the half hourly time-mean basis. As the mean wind speed $\overline{w_{a}}$ is too small to be monitored moreover subject to errors due to any possible vertical misalignment of used anemometer and resulting vertical speed biases, an assessment of $F_{c}$ should be rather based on the evaporation rate. Since most of the used analyzers for eddy covariance measurements are providing water vapor content, monitoring it along with water vapor turbulent transport allows through few simplifications to deduce water vapor production and then corresponding air volume increase. Indeed, water vapor turbulent flow $F$ measured by eddy covariance setup corresponds to water vapor production $P$ and its stockage $S$ variation under EC level.

$75 F=P-\frac{d s}{d t}$

For production determination, supposing mean flux being turbulent, we need to know the stock between soil surface and eddy covariance setup height. This can be achieved using few traditional capacitive sensors for usual water vapor stockage monitoring since only time-averaged values are required. For an order of graders estimation of gas fluxes and energies correction, on can neglect stockage variation and use only eddy covariance data. For this purpose, a real data set of our EC instrumented site (enclosed path IRGA analyzer Li-7200 from LI-COR Biosciences, Lincoln, Nebraska USA and sonic anemometer Gill HS-50 from Gill Instruments Limited, Lymington Hampshire, UK) ICOS network, Fr-Lam, during 11 months of 2018 with a winter wheat crop followed by an intermediate crop and provided by a implemented SmartFlux2 with embedded EddyPro software (LI-COR Biosciences, Lincoln, Nebraska USA) were used.

85 On a half hourly base, first should be estimated the mean vertical air speed $\overline{w_{a}}$. As this speed results from water vapor formation, assuming water vapor stockage variation negligibility and mean water vapor transport being turbulent, production is equal to water vapor flow $F^{\mathrm{H}_{2} \mathrm{O}}$. Supposing water vapor being a perfect gas, corresponding mean volume occupied by water vapor with a square meter surface base will have a hight $h$ given by Eq. (5)

$h=\frac{n * R * \overline{T_{a}}}{\overline{P_{a}}}$

90 With $\mathrm{R}$ being perfect gas constant, $n$ number of produced water vapor mols, $\overline{T_{a}}$ mean air temperature (supposed to be uniform and the same as the formed water vapor temperature) and $\overline{P_{a}}$ mean air pressure (supposed to be uniform and the 
same as the formed water vapor pressure). Supposing air pressure the same at EC level and at evaporation level (soil level for soil evaporation or leaf level for vegetation transpiration) is realistic. The same supposition for air temperature is less realistic but, this is not very important since water vapor, once formed at some temperature, during its trip from evaporation level to EC level, will acquire air temperature expending or collapsing accordingly. Vertical mean air speed is sensible to the whole air volume expansion below EC level and then, supposing water vapor formation at EC level air temperature, or water vapor formed at a different temperature reaching EC air temperature progressively is the same from the volume expansion point of view.

By temporal derivation considering initially water vapor flux as only turbulent $F_{E C}^{\mathrm{H}_{2} \mathrm{O}}$ (with $\left[\mathrm{F}_{E C}^{\mathrm{H}_{2} \mathrm{O}}\right]=\mathrm{mol} / \mathrm{m}^{2} / \mathrm{s}$ ) we obtain the 100 first pass mean vertical air speed $\overline{w_{a 1}}$ by Eq. (6):

$\overline{w_{a 1}}=\frac{F_{E C}^{H_{2} O} * R * \overline{T_{a}}}{\overline{P_{a}}}$

With this value using mean water vapor molar density $\overline{d_{\mathrm{H}_{2} \mathrm{O}}}$ we obtain the correction water vapor flux bay Eq. (7) $F_{C}^{H_{2} O}=\overline{w_{a 1}} * \overline{d_{H_{2} O}}$

Since $\mathrm{F}_{C} \mathrm{H}_{2} \mathrm{O}$ is in the rage of $1 \%$ of $F_{E C}^{\mathrm{H}_{2} \mathrm{O}}$ it will not be necessary to recalculate again a new correction by iteration up to reach

105 a stable value for total water vapor flux $F^{\mathrm{H}_{2} \mathrm{O}}$ and for the rest of the assessment we may retain this value given by Eq. (8)

$F^{\mathrm{H}_{2} \mathrm{O}}=F_{E C}^{\mathrm{H}_{2} \mathrm{O}}+F_{C}^{\mathrm{H}_{2} \mathrm{O}}$

Recalculated vertical mean air speed $\overline{w_{a}}$ uses the corrected water vapor flux from Eq. (8) and is given by Eq. (9)

$\overline{w_{a}}=\frac{F^{H_{2} O_{* R *}} \overline{T_{a}}}{\overline{P_{a}}}$

110 With this speed, all gases and energies fluxes can be corrected as following:

Carbon dioxide flux:

$F_{C}^{\mathrm{CO}_{2}}=\overline{w_{a}} * \overline{d_{\mathrm{CO}_{2}}}$

Sensible heat flux:

$H_{c}=\rho_{a} * c_{p} * \overline{w_{a}} * \overline{T_{a}}$

115 Latent heat:

$L E_{c}=F^{\mathrm{H}_{2} \mathrm{O}} * \lambda * M_{\mathrm{H}_{2} \mathrm{O}}$

With $\overline{d_{\mathrm{CO}_{2}}}$ being mean carbon dioxide molar density, $\rho_{a}$ being air mass density, $c_{p}$ being air heat capacity (given by SmartFlux 2 computations but can be calculated independently based on dry air and water vapor heat capacities, RH and air temperature), $\lambda$ being evaporation water latent heat depending on air temperature $\overline{T_{a}}$ and given by Eq. (13), and $M_{\mathrm{H}_{2} \mathrm{O}}$ being

120 water molar mass $(18.01528 \mathrm{~g} / \mathrm{mol})$ :

$\lambda=\left(3147.5-2.372 * \overline{T_{a}}\right)$ in $\mathrm{J} / \mathrm{g}$ or $\mathrm{kJ} / \mathrm{kg}$ 
This time, assuming temperature of the evaporating water being the same as air temperature is not strictly speaking correct but the difference of $\lambda$ for a $10 \mathrm{~K}$ (or $10^{\circ} \mathrm{C}$ ) temperature difference is only $0.75 \%$ wide. Then a committed error equating evaporation temperature to air temperature at $\mathrm{EC}$ level is acceptable.

\section{Results and discussion}

For results comparison over concerned time lapse (during the 11 first months of 2018 year), an integration of all fluxes rather than their instantaneous values is reported in order to avoid excessive fluctuations and to display most important information which is the totalized flux.

As shows fig. 1, carbon dioxide flux is greatly affected by water evaporation and its flux correction $\left(115 \mathrm{~g}\right.$ equivalent $\mathrm{C} / \mathrm{m}^{2}$

130 during 11 months) that reach about $45 \%$ of the annual NEP of winter wheat and intermediate crop in relatively good agreement with a very rough estimation following the argumentation given in sect. 2.2. (116 g equivalent $\mathrm{C} / \mathrm{m}^{2}$ for 11 months of 2018 rainfall: $650 \mathrm{~mm}$ ). This underestimation of carbon dioxide flux by EC technique was largely observed by comparison with other techniques such as closed chambers techniques and pointed out by numerous authors (Goulden et al. 1996, Norman et al. 1997, Law et al. 1999, Hollinger et al. 1999, Janssens et al. 2000, Pavelka et al. 2007, Zha et al. 2007,

135 Myklebust et al. 2008, Schrier-Uijl et al. 2010). Figure 2 and fig. 3 show respectively integrated water vapor and LE fluxes. As LE and water vapor flux are almost proportional, their relative correction importance is the same and only of about $1.3 \%$. Sensible heat flux (fig. 4) shows an important variation after correction of 33\% (EC underestimation of $H$ was pointed by Moorhead et al. 2019) and total energies flux ( $\mathrm{LE}+\mathrm{H})$ variation is about $13 \%$. This point may, in part, explain a EC systemic energy balance closure leak (Barr et al. 1994, Twine et al. 2000, Finnigan et al. 2003, Meyers and Hollinger 2004, Barr et al. 2006 or Foken 2008) especially under low turbulence condition (since then evaporation correction is more important comparatively to the turbulent flux given by EC) pointed out by Moore (1976) or Goulden et al. (1996). Bowen ratio is also affected since it is defined by a quotient of sensible heat by latent heat $H / L E$ and with the assessed variation of both energies: $\mathrm{H}$ is largely underestimated but LE is not. Consequently, after correction we may expect an increase of about $30 \%$ for Bowen ratio in accordance with observation related by Wolf et al. (2008).

145 Water vapor formation corresponds to a notable volume expansion. This expansion increases the mean vertical air speed which remains weak but affects sensibly oscillating fluxes. Indeed, any considered flux, in its instantaneous values, is much bigger than the correction value resulting from not nil mean vertical air speed and due to water evaporation. However, if the fluxes are oscillating such as $F^{\mathrm{CO}_{2}}$, changing its sign between night and day, after additions, their cumulation reaches a mean value which is relatively low. As an illustration, we can consider two functions: $A(t)=\sin (w t)$ and $B(t)=\sin ^{2}(w t)$. In

150 their absolute values, $|A(t)| \geq|B(t)|$ but after integration on an interval long enough comparatively to their oscillation period: $\int A(t) d t \ll \int B(t) d t$.

More a considered flux is oscillating around zero and relatively bigger will be its correction due to the water evaporation. Carbon dioxide flux is oscillating much more than water vapor flux, then the former correction is of a relatively high 

(evapotranspiration on a vegetated plot) do not invalidate usual corrections that are supposing mean vertical air speed nullity such as Webb-Pearman-Leuning (WPL) correction since instantaneous values of the mean vertical speed are very small and assumed its nullity is used to compare vertical dry air velocity versus vertical water vapor velocity. Only, on the half hourly basis, corresponding corrections have to be applied.

\section{Conclusions}

Webb et al. (1980) introduced eddy covariance corrections due to the water vapor propagations and resulting air density fluctuations. Supplementary corrections proposed here consist to take into account water vapor formations and resulting air volume expansion. All gas and energies flux can be easily assessed using usual EC measurements and results are matching most of the observed EC discrepancies: underestimation of carbon dioxide flux, underestimation of sensible heat flux, underestimation of Bowen ratio or even energy balance closure leak.

Competing interests. The author declares that he has no conflict of interest.

Acknowledgements. The EC setup on Fr-Lam site was mainly founded by ICOS France. I would like to acknowledge my colleagues, especially Franck Granouillac and Pierre-Alain Pratz, for their help building and maintaining our instrumental setups and OSR for support.

\section{References}

Aubinet, M., Vesala, T., and Papale, D.: Eddy Covariance, A Practical Guide to Measurement and Data Analysis, Springer

Dordrecht Heidelberg London New York, doi:10.1007/978-94-007-2351-1, 2012.

Barr, A. G., King, K. M., Gillespie, T. J., Den Hartog, G, and Neumann, H. H.: A comparison of bowen ratio and eddy correlation sensible and latent heat flux measurements above deciduous forest, Boundary-Layer Meteorol., 71, 21-41, doi:10.1007/BF00709218, 1994.

Barr, A. G., Morgenstern, K., Black, T. A., McCaughey, J. H., and Nesic, Z.: Surface energy balance closure by the eddy180 covariance method above three boreal forest stands and implications for the measurement of the CO2 flux, Agric. For. Meteor., 140 (1-4), 322-337, doi:10.1016/j.agrformet.2006.08.007, 2006.

Burba, G. and Anderson, D.: A Brief Practical Guide to Eddy Covariance Flux Measurements: Principles and Workflow Examples for Scientific and Industrial Applications, published by LI-COR Biosciences. 
Finnigan, J. J., Clement, R., Malhi, Y., Leuning, R., and Cleugh, H. A: A re-evaluation of long-term flux measurement techniques. Part 1: Averaging and coordinate rotation, Bound. Layer Meteor, 107, pp. 1-48, doi:10.1023/A:1021554900225, 2003.

Foken, T.: The energy balance closure problem — an overview, Ecol. Appl. 18 (6), 1351-1367, doi:10.1890/06-0922.1, 2008.

Goulden, M. L., Munger, J. W, Fan, S-M., Daube, B. C., and Wofsy, S. C.: Measurements of carbon sequestration by longterm eddy covariance: methods and a critical evaluation of accuracy, Glob. Change Biol., 2, 169-182, doi:10.1111/j.1365-

Hao, X. M., Li, C., Guo, B., Ma, J. X., Ayup, M., and Chen, Z. S.: Dew formation and its long-term trend in a desert riparian forest ecosystem on the eastern edge of the Taklimakan Desert in China, J. Hydrol. ,472-473, 90-98, doi:10.1016/j.jhydrol.2012.09.015, 2012.

Hollinger, D.Y., Goltz, S. M., Davidson, E. A., Lee, J. T., Tu, K., and Valentine, H. T.: Seasonal patterns and environmental

195 control of carbon dioxide and water vapor exchange in an ecotonal boreal forest, Glob. Change Biol., 5, 891-902, doi:10.1046/j.1365-2486.1999.00281.x, 1999.

Janssens, I. A., Kowalski, A. S., Longdoz, B., and Ceulemans, R.: Assessing forest soil CO2 efflux: an in situ comparison of four techniques, Tree Phys., 20, 23-32, doi:10.1093/treephys/20.1.23, 2000.

Law, B. E., Baldocchi, D. D., and Anthoni, P. M.: Below canopy and soil CO2 fluxes in a ponderosa pine forest, Agric. For.

200 Meteor., 94, 171-188, doi:10.1016/s0168-1923(99)00019-2, 1999.

Meyers, T. P. and Hollinger, S. E.: An assessment of storage terms in the surface energy balance of maize and soybean, Agric. For. Meteor., 125, 105-115, doi:10.1016/j.agrformet.2004.03.001, 2004.

Montgomery, R. B.: Vertical eddy flux of heat in the atmosphere. J. Meteorol., 5, 265-274, doi:10.1175/1520-0469(1948)005<0265:VEFOHI>2.0.CO;2, 1948.

205 Moore, C. J.: Eddy flux measurements above a pine forest, Quarterly J. of the Royal Meteo. Sc., 102, 434, 913-918, doi:10.1002/qj.49710243418, 1976.

doi:10.1016/j.agrformet.2008.06.016, 2008.

Moorhead, J. E., 1, Marek, G. W., Gowda, P. H., Lin, X., Colaizzi, P. D., Evett S. R., and Kutikoff, S.: Evaluation of Evapotranspiration from Eddy Covariance Using Large Weighing Lysimeters, Agronomy, 9(2), 99,

210 doi:10.3390/agronomy9020099, 2019.

Myklebust, M.C., Hipps, L. E., and Ryel, R. J.: Comparison of eddy covariance, chamber, and gradient methods of measuring soil CO2 efflux in an annual semi-arid grass, Bromus tectorum, Agric. For. Meteor., 148 (11), 1894-1907,

Norman, J. M., Kucharik, C. J., Gower, S. T., Baldocchi, D. D., Crill, P. M., Rayment, M., Savage, K., and Striegl, R. G.: A comparison of six methods for measuring soil-surface carbon dioxide fluxes, J. Geophys. Res., 102, 28771-28777, 215 doi:10.1029/97JD01440, 1997.

Obukhov, A M: Характеристика микроструктуры ветра в приземном слое атмосферы (Characteristics of the microstructure of the wind in the surface layer of the atmosphere), Izv AN SSSR ser Geofiz, 3, 49-68, 1951. 
Oki, T. and Kanae, S.: Global hydrological cycles and world water resources, Science, 313, 1068-1072, doi:10.1126/science.1128845, 2006.

220 Pavelka, M, Sedlák, P., Acosta, M., Czerný, R., Taufarová, K., and Janouš, D.: Chamber techniques versus eddy covariance method during nighttime measurements, International Scientific Conference, Slovakia, Střelcová, K., Škvarenina, J., and Blaženec, M. (eds.). 2007.

Satar, E., Berhanu, T. A., Brunner, D., Henne, S., and Leuenberger, M.: Continuous CO2/CH4/CO measurements (20122014) at Beromünster tall tower station in Switzerland, Biogeosciences, 13, 2623-2635, doi:10.5194/bg-13-2623-2016, 2252016.

Schrier-Uijl, A. P., Kroon, P. S., Hensen, A., Leffelaar, P. A., Berendse, F., and Veenendaal, E. M.: Comparison of chamber and eddy covariance-based $\mathrm{CO} 2$ and $\mathrm{CH} 4$ emission estimates in a heterogeneous grass ecosystem on peat, Agric. For. Meteor., 150(6), 825-831, doi:10.1016/j.agrformet.2009.11.007, 2010.

Swinbank, W. C.: The measurement of vertical transfer of heat and water vapor by eddies in the lower atmosphere, $\mathrm{J}$ 230 Meteorol, 8, 135-145, 0.1175/1520-0469(1951)008<0135:TMOVTO >2.0.CO;2, 1951.

Twine, T. E., Kustas, W. P., Norman, J. M., Cook, D. R., Houser, P. R., Meyers, T. P., Prueger, J. H., Starks, P. J., and Wesely, M. L.: Correcting eddy-covariance flux underestimates over a grassland, Agric. For. Meteor., 103, 279-300, doi:10.1016/S0168-1923(00)00123-4, 2000.

Webb, E. K., Pearman, and G. I., Leuning, R.: Correction of flux measurements for density effects due to heat and water235 vapor transfer, Q. J. R. Meteorol. Soc., 106 (447), 85-100, doi:10.1002/qj.49710644707, 1980.

Wolf, A., Saliendra, N., Akshalov, K., Johnson, D. A., and Laca, E.: Effects of different eddy covariance correction schemes on energy balance closure and comparisons with the modified Bowen ratio system, Agric. For. Meteor., 148, 942-952, doi:10.1016/j.agrformet.2008.01.005, 2008.

Zha, T., Niinisto, S., Xing, Z., Wang, K. Y., Kellomäki, S., and Barr A. G.: Total and component carbon fluxes of a Scots 240 pine ecosystem from chamber measurements and eddy covariance, Ann Bot.; 99(2), 345-53, doi:10.1093/aob/mcl266, 2007. 
https://doi.org/10.5194/bg-2020-43

Preprint. Discussion started: 28 February 2020

(C) Author(s) 2020. CC BY 4.0 License.

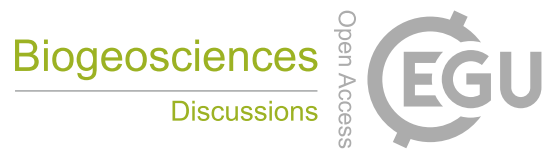

(c) (i)

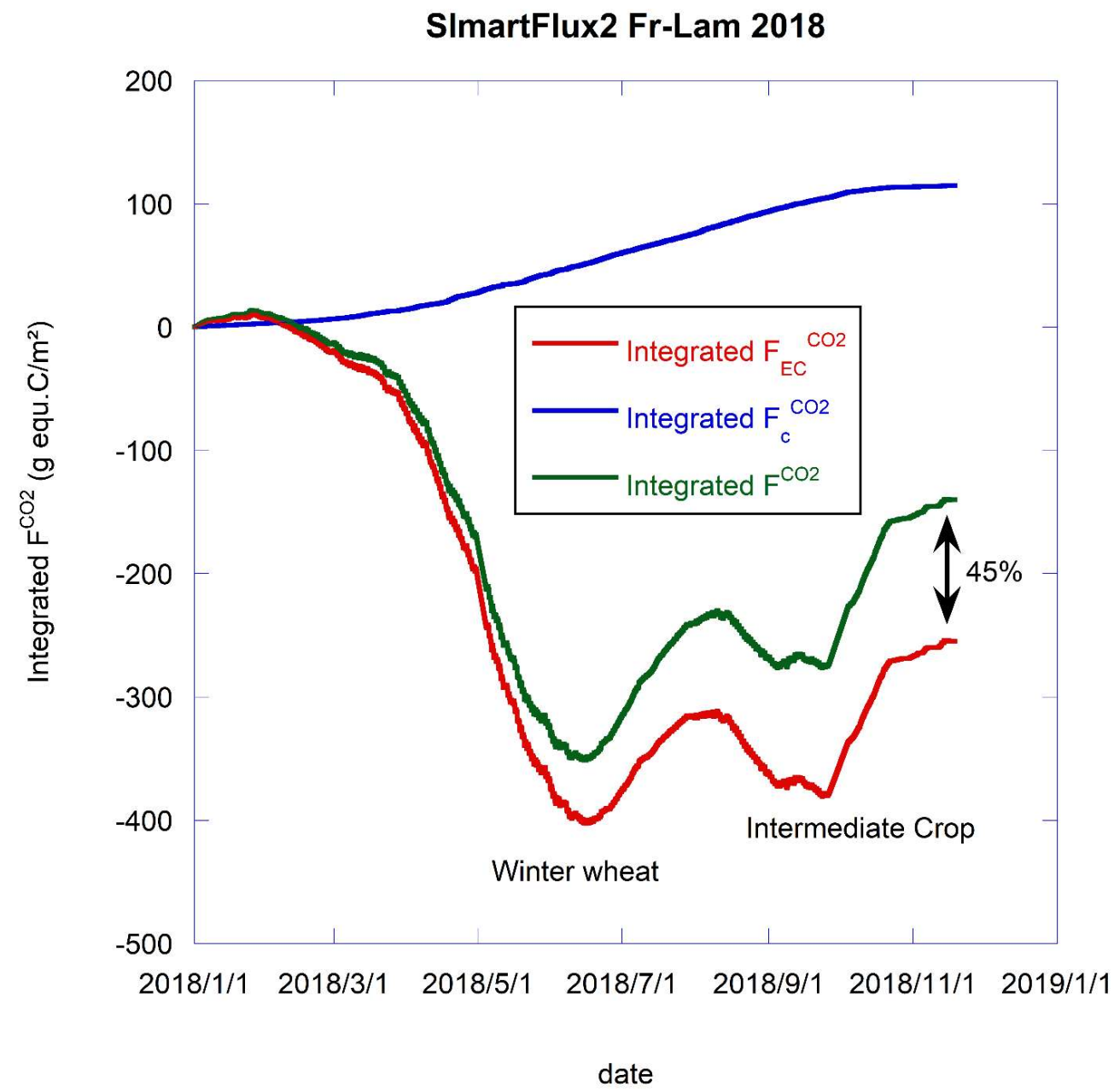

Figure 1: Integrated EC measured carbon dioxide flux before, after correction and correction part. 
https://doi.org/10.5194/bg-2020-43

Preprint. Discussion started: 28 February 2020

(c) Author(s) 2020. CC BY 4.0 License.
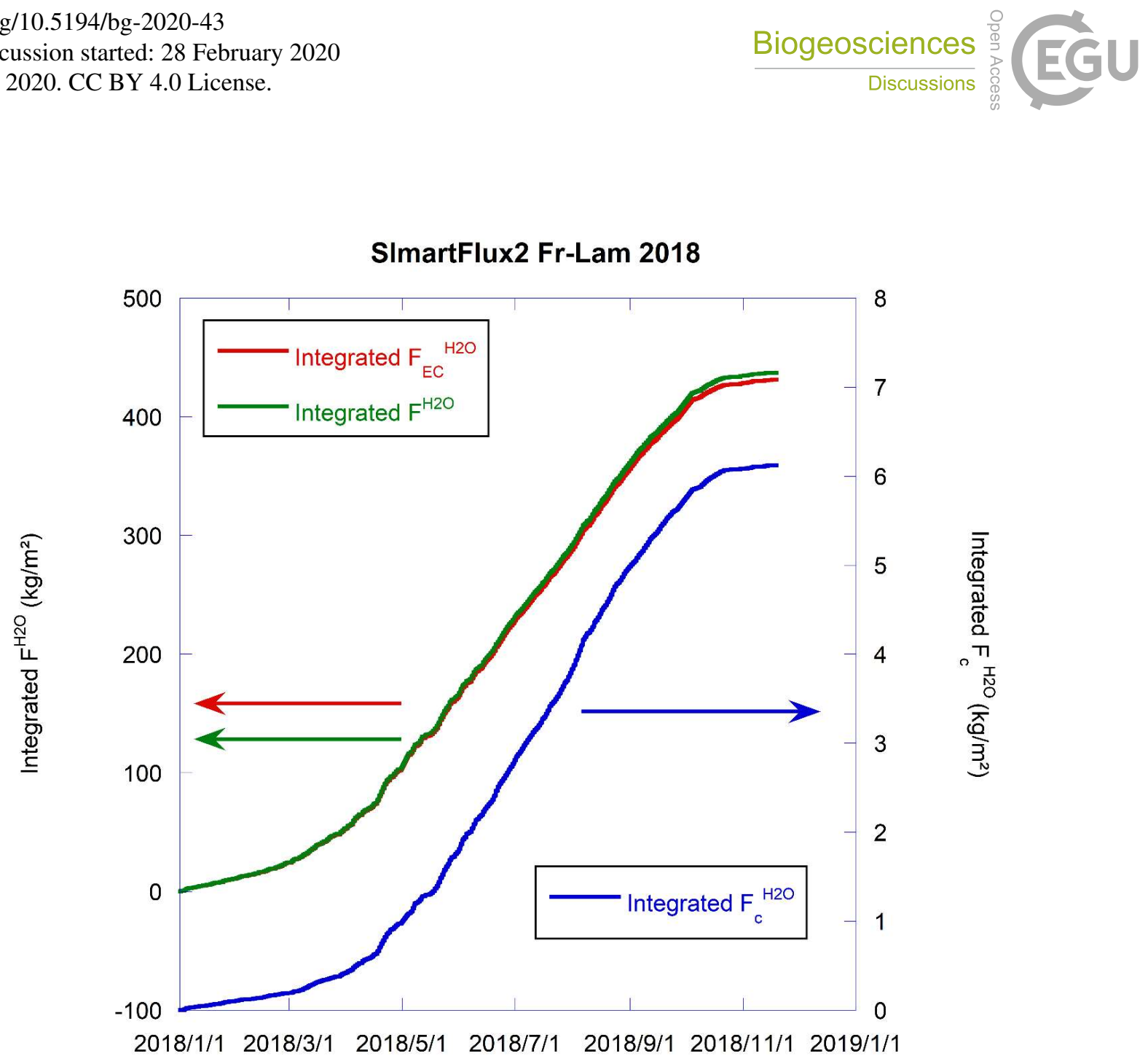

date

245 Figure 2: Integrated EC measured water vapor flux before, after correction and correction part. 
https://doi.org/10.5194/bg-2020-43

Preprint. Discussion started: 28 February 2020

(c) Author(s) 2020. CC BY 4.0 License.
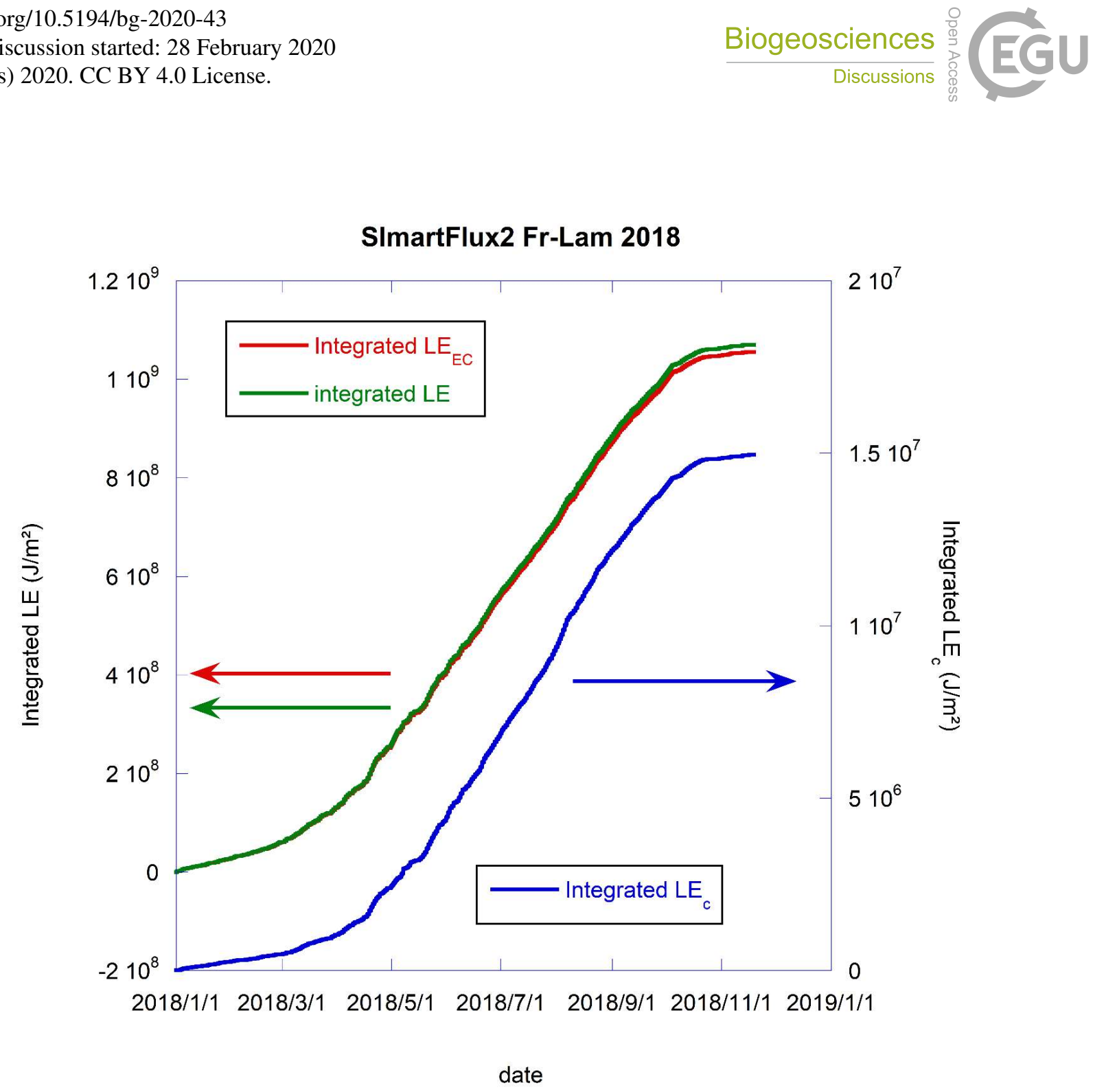

Figure 3: Integrated EC measured latent water evaporation heat flux before, after correction and correction part. 
https://doi.org/10.5194/bg-2020-43

Preprint. Discussion started: 28 February 2020

(C) Author(s) 2020. CC BY 4.0 License.

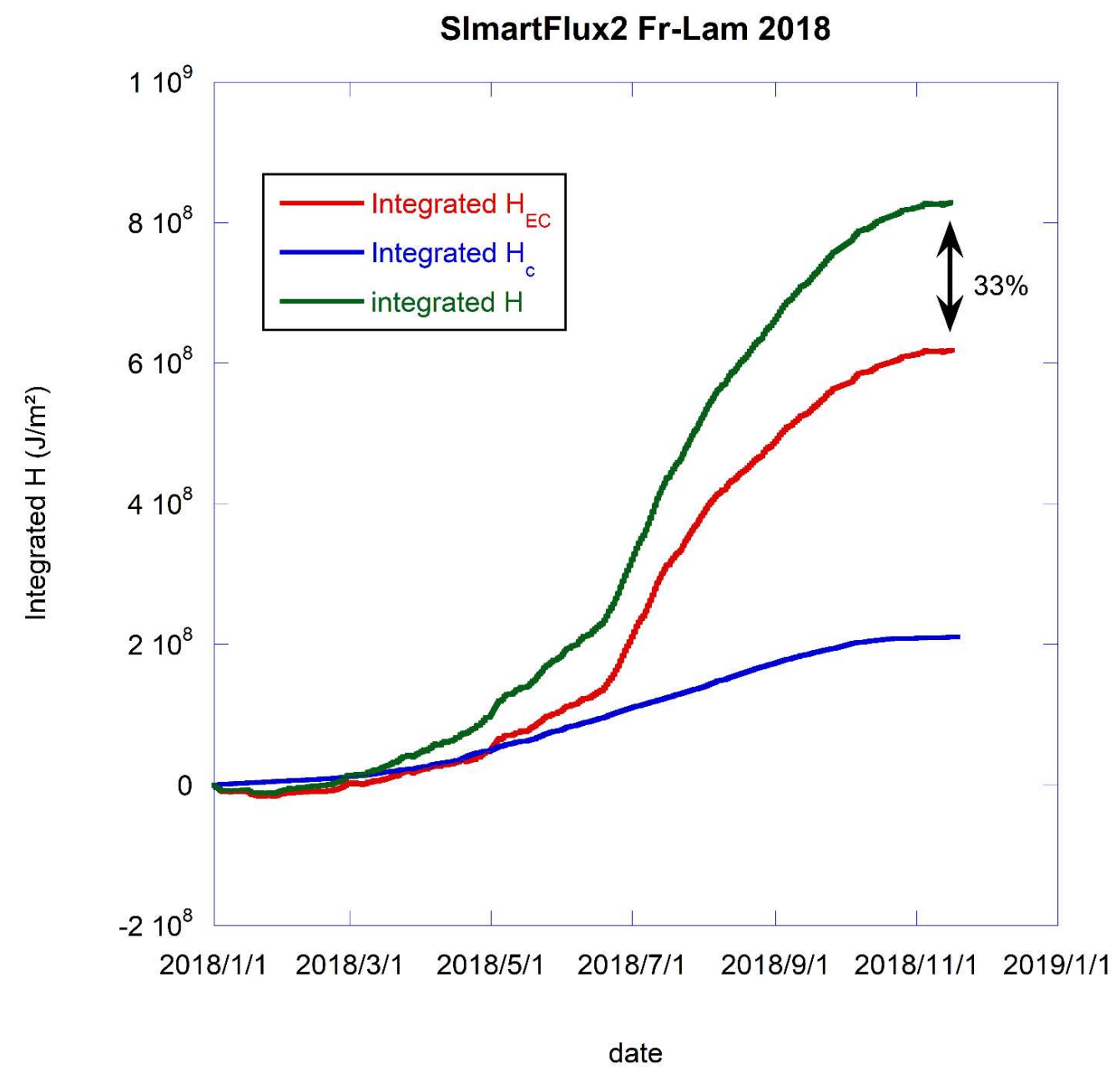

Figure 4: Integrated EC measured sensible heat flux before, after correction and correction part. 